\title{
The cost-effectiveness of conventional discectomy compared to other surgical techniques for lumbar disk herniation. A systematic review
}

\author{
Thorsen $\mathrm{MTH}^{1 *}$, Ødegaard-Olsen $\emptyset^{1}$, Yde $\mathrm{CL}^{2,3}$, Andersen $\mathrm{MO}^{2,3}$, Draborg $\mathrm{E}^{1,4}$ and O Neill $\mathrm{S}^{2,3}$ \\ ${ }^{1}$ Faculty of Health Sciences, University of Southern Denmark, Campusvej 55, 5000 Odense M, Denmark \\ ${ }^{2}$ Spine Center of Southern Denmark, Lillebælt Hospital, Østre Hougvej 55, 5500 Middelfart, Denmark \\ ${ }^{3}$ Institute of Regional Health Research, University of Southern Denmark, Campusvej 55, 5000 Odense M, Denmark \\ ${ }^{4}$ COHERE, Centre for Health Economics Research, University of Southern Denmark, Odense, Denmark
}

\begin{abstract}
Background: The current study reviews the literature on the cost-effectiveness of conventional diskectomy compared to other surgical techniques, by assessing studies with economical evaluation and studies using proxy measures of cost-effectiveness.

Methods: In April 2016, a comprehensive search was conducted in Medline, Embase and the Cochrane Database. Reference lists of retrieved articles were perused for further relevant publications. Randomized controlled trials and comparison studies, comparing conventional diskectomy to other surgical interventions for patients with lumbar disk herniation, were included and reviewed by the authors. Data were gathered on the methodology of the studies, including study design, randomization, follow-up period, cost-estimation, etc. and the quality of the published studies was quantified using a modified version of the Drummond checklist.

Results: Twenty-four articles were included in the review, 9 retrieved from the original search, and an additional 15 from reference lists. Four studies included an economical evaluation and 20 reported proxy measures of cost-effectiveness. The quality of studies varied considerably and results were ambiguous; the four economic studies favored conventional diskectomy, but none were randomized trials. Of the twenty proxy studies some favored the alternatives, and some reported no clear difference.
\end{abstract}

Conclusions: The available literature does not allow for strong conclusions due to the sparsity of high quality economic studies. The available evidence, however, suggests that any cost-effectiveness difference between conventional diskectomy and the alternatives is unlikely to be great.

\section{Introduction}

Compared to many other spinal surgeries, diskectomy is a relatively inexpensive procedure, but radiculopathy due to lumbar intervertebral disk herniation is one of the most common spinal disorder requiring surgical intervention. Thus, the relative cost effectiveness of different, competing surgical techniques is worthy of investigation, if limited resources are to be used rationally. Unfortunately, a reliable estimate of direct and indirect costs can be difficult to ascertain.

In Denmark, for instance, surgery for lumbar disk herniations may account for as much as one third of all lumbar spinal surgery [1] and while the direct costs can be estimated through the use of a national database [2] (approximately 35.000DKK / 5200 US\$ or 4600 Euro per operation), there is no simple way to estimate indirect costs related to sick-leave, lost production, etc. Between 2009 and 2013 more than 6000 surgeries for lumbar disk herniation were performed in Denmark alone ${ }^{3}$. The cost and frequency of disk surgery may differ between countries, but in general disk surgery is a relatively common intervention and although direct costs are obviously significant, indirect costs are likely to be far more important. Especially so, as disk herniations tends to affect individuals of working age [3].

Conventional open diskectomy (CD) is considered an effective treatment for selected patients with lumbar disk herniation with radicular pain ${ }^{4}$. In the last 30 years the success rates for sciatic pain has been reported in the range between $49 \%$ and $98 \%$, depending on patient selection, duration of symptoms, success criteria, length of follow-up, etc $[4,5]$.

A number of alternative surgical procedures have been and continue to be used in the treatment of lumbar disk herniation. For example, lumbar microdiskectomy (MD) has gained widespread acceptance $^{6}$ and studies suggest that the procedure may be effective and associated with shorter hospital stay and earlier return to work compared to CD [5,7-9]. Conversely, the use of chemonucleolysis (CNL) which became popular in the 1970s and 1980s, has largely been replaced by other surgical techniques which do not expose patients to the allergic complications inherent to CNL [8].

Correspondence to: Thorsen MTH, Faculty of Health Sciences, University of Southern Denmark, Campusvej 55, 5000 Odense M, Denmark, Tel: +47 93618 222; E-mail: Mayt101@yahoo.no

Key words: literature review, intervertebral disk, intervertebral disc, surgery, herniation, prolapse, discectomy, discectomy, radiculopathy, cost-effectiveness

Received: February 26, 2018; Accepted: March 16, 2018; Published: March 19, 2018 
Which surgical technique should be considered the standard or reference technique for lumbar disk herniation is a matter of debate and different surgeons have different preferences. Benz \& Garfin [10], state that $\mathrm{CD}$ remains the gold standard, while Postacchini \& Postacchini [8] claim that MD should be considered the gold standard. In 2012, CD was the most commonly used surgical procedure in the treatment of patients with lumbar disk herniation in Denmark (59\%) [1] and thus $\mathrm{CD}$ was chosen as the standard (index treatment) in this literature review.

Cost-effectiveness analysis is useful for identifying the most efficient use of health-care resources for a specific health condition, i.e. which of a number of alternative interventions offers most value for money. Cost-effectiveness studies can help clinicians and administrators make necessary decisions about choice of treatment on a rational basis [11]. To our knowledge there are no literature reviews reporting the costeffectiveness of $\mathrm{CD}$ compared to other surgical techniques used for treating lumbar disk herniation.

The current study was conducted to determine whether the literature supports $\mathrm{CD}$ as being more cost-effective than other surgical techniques for lumbar disk herniation, by reviewing studies using a cost-effective analysis and studies that report proxy measures of costs. In this context, proxy measures of cost are defined as length of hospitalization, number of sick-leave days, disability requiring treatment, and cost of intervention.

\section{Materials and methods}

A literature review was conducted in accordance with the Prisma statement [12]. The review team consisted of two reviewers, $\varnothing O$ and MT. Any disagreement in manuscript review was solved by conferring with a health economy expert (Eva Draborg - ED) at the Center of Health Economic Research (COHERE), University of Southern Denmark in Odense, Denmark.

\section{Eligibility criteria}

Participants: Studies in which participating patients had a radiologically verified lumbar disk herniation.।

Study design: Randomized controlled trials, non-randomized clinical trials and comparison studies.

Intervention: Conventional diskectomy compared to other surgical interventions.

Area: Europe and North-America.

Language: English or Scandinavian languages.

Economic evaluation: Cost-effectiveness analysis or proxy-measures of cost.

\section{Information sources}

The following databases formed the basis for a systematic literature search: Medline (Pubmed format), Embase and Cochrane, which also contain the NHS economic evaluation database. In addition, the reference lists of all relevant articles, found by the original search strategy, was examined manually.

The date of last search was the 13th of April 2016.

To ensure that the search strategy and method was optimal, a senior librarian with particular experience and expertise in systematic reviews was consulted (Berit Elisabeth Alving, University of Southern Denmark).

\section{Search}

The search strategy was composed of the following PICO elements (patients, intervention, control, outcome): P: Patients with lumbar disk herniation radiologically verified, I: Conventional diskectomy, C: Other surgical techniques and O: Cost-effectiveness or cost-benefit. The exact search string is shown in Appendix 1-3.

\section{Study selection}

Figure 1 illustrates the literature identification and review process as performed by both reviewers. The reviews were performed in parallel, but independently and blinded by each reviewer.

All articles were screened for inclusion criteria, first by title, then by abstract, and then in entirety. Articles fulfilling the inclusion criteria were included in the review.

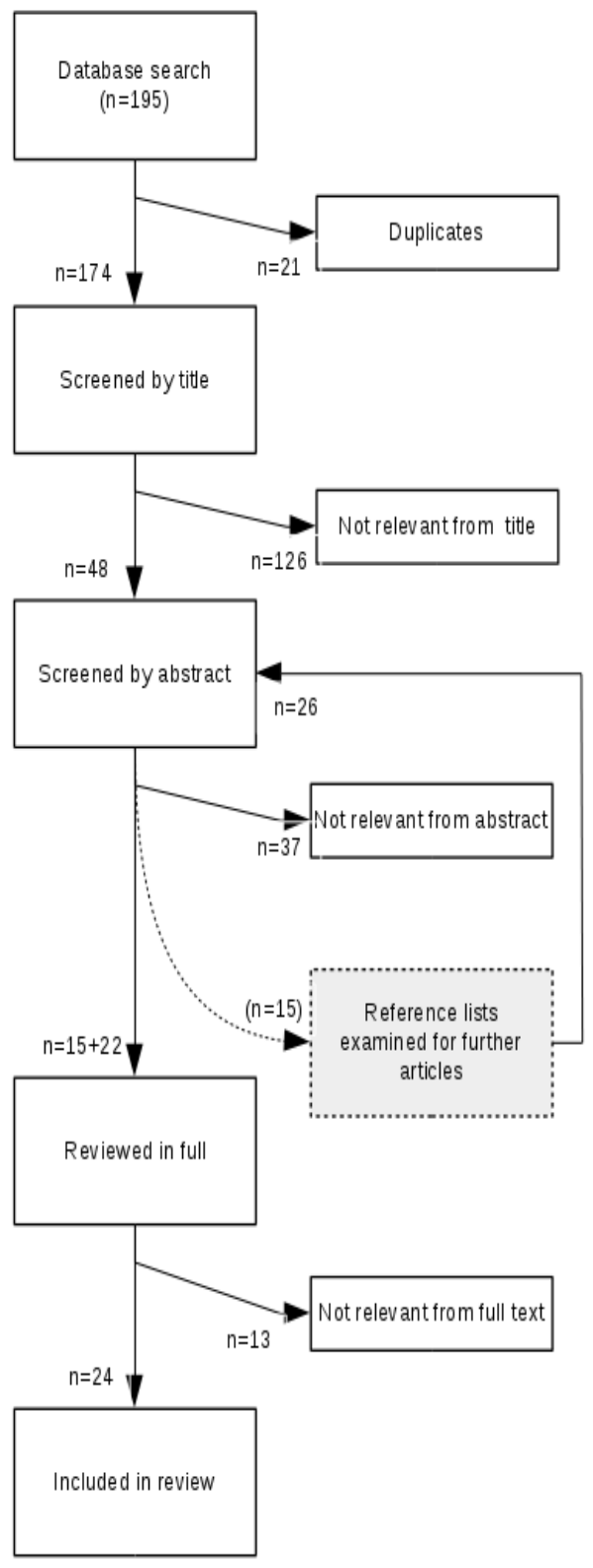

Figure 1. Literature search and review flow. The grey box indicates additional articles $(n=15)$ identified by perusal of reference lists of articles from the original database search which made it through to abstract screening $(n=48)$. 


\section{Data collection process}

Data was extracted on methodology and results using a modified version of the checklist by Drummond, et al [13] (Table 1 and Appendix 4).

\section{Data items}

The checklist by Drummond, et al [13] is specifically designed for studies with an element of economic evaluation and is used extensively in the literature as a gold standard for economical evaluations.

In the present study, the checklist was modified with a further 3 items being added:

1. "Follow-up same for all?" was added to assess comparable followup periods between study groups.

2. "Was a method of randomization used or were the groups similar at baseline?" was added to assess baseline comparability between study groups.

3. "Was the withdrawal/dropout rate described?" was added to assess drop-out bias.

\section{Risk of bias in individual studies}

The same checklist was used in all studies, with and without a specific economic evaluation, but checklist items that related specifically to an economic evaluation (questions 7 to 12) were omitted in studies which did not include such an analysis. This was done, to avoid excessive bias against otherwise methodologically sound studies, which had not been designed with such in-depth economic analysis in mind.

All items on the checklist were conferred with a health-economy expert (ED) prior to study assessment, to ensure that the reviewers had a common understanding of the assessment parameters.

Reviewers 1 and 2 assessed each study independently and subsequently compared their findings. All studies which included an economic evaluation as well as those studies where reviewer 1 and 2 were not in agreement, were conferred individually with the health economy expert until a consensus was reached.

\section{Results}

\section{Search strategy}

The literature search revealed a total of 195 articles (Medline 141, Embase 43 and the Cochrane database 11) - see appendix 1-3. After removal of duplicates 174 articles remained.

Onehundred-and-twenty-six were deemed not eligible for inclusion, based on the title alone and of the 48 remaining articles, 15 were deemed potentially relevant based on the abstracts [11,14-27]. Examination of the reference lists of these articles revealed another 26 articles of potential interest.

Based on the abstracts 37 studies were deemed potentially relevant and reviewed in full -- 15 from the database search and a further 22 from the references lists. On review of the full article texts, a further 13 were found not to fulfill the inclusion criteria ( 3 without intervention, 8 did not contain CD as an option, and 2 were written in French).

Ultimately 24 articles were included in the review, 9 retrieved from the original search, and 15 from manual reference list perusal. Five articles were conferred with the health-economist (ED) due to conflicting evaluations by reviewers 1 and 2 .

The included manuscripts are summarized in Table 2 in descending order of quality, as assessed by the quality checklist. The quality assesment of each manuscript is detailed in table 3.

\section{Description of results}

The 24 relevant studies were published in the period between 1983 and 2016 (Table 1). Four of them included economical evaluations [28-31] and 20 used proxy measures [32-51]. Eight were randomized controlled trials (RCTs) and 16 were non-randomized comparison studies.

Eleven studies compared CD to CNL [29-32,36,37,41,42,49-51]. The outcome measures used were length of hospitalization in six studies [30-32,36,37,42], length of sick leave in four studies [43,48,50,51], disability in two studies ${ }^{37,48}$, and cost of intervention in five studies [29$31,42,43]$.

Table 1. Quality criteria. Checklist used for quality assessment, based on the checklist by Drummond, et al [13].

\begin{tabular}{|l|l}
\hline Question & Criteria for "yes"
\end{tabular}

1. Follow-up period same for all?

2. Was a method of randomization used to allocate the patients? OR Are the groups similar at baseline?

3. Was the withdrawal/dropout rate described?

Was the timing of follow-up identical for both intervention groups?

Was a random (unpredictable) assignment sequence use to allocate the patients? OR Were the two groups similar on the given parameters e.g. sex, age distribution?

The number of participants who were included in the study but did not complete the observation period or were not included in the analysis are described and reasons are given? Is it clear what the authors were trying to do?

4. Was a well-defined question posed in an answerable form?

5. Was a comprehensive description of the competing alternatives given?

Was conventional diskectomy and the control intervention explicitly described?

6. Was there evidence that the program's effectiveness had been established?

7. Were all the important and relevant outcomes and costs for each alternative identified? Was it clearly whether the criteria for treatment effectiveness had been met? If something is not worth doing, it's not worth doing well. Does the surgeon do more good than harm? Were all important cost and outcomes identified depending on what perspective(s) was/were taken (e.g. health provider, patient, society)?

8. Were outcomes and costs measured accurately in appropriate units prior to evaluation?

Was the cost quoted in appropriate units: the hours working time, number of visits, lost workdays, 'gained life years'

\begin{tabular}{l|l}
9. Were the outcomes and costs valued credibly? & Were cost and outcome measures valued correctly?
\end{tabular}

10. Were outcomes and costs adjusted for different times at which they occurred (discounting)?

11. Was an incremental analysis of the outcomes and costs of alternatives performed?

12. Was a sensitivity analysis performed?

13. Did the presentation and discussion of the results include all, or enough, of the issues that are of concern to users?

Were all outcomes and costs adjusted to current values?

Were the incremental costs analyzed in relation to the additional benefit it delivers?

Were all the main areas of uncertainty considered and described by a sensitivity analysis?

Have the authors of the article discussed weaknesses in the analysis and how they reached their results? Helping the reader to interpret the results. 
Table 2. Article summaries

\begin{tabular}{|c|c|c|c|c|c|c|c|c|}
\hline Study & Country & Design & Control & Sample & CD age & Control age & Follow up & $\begin{array}{l}\text { Economic } \\
\text { eval. }\end{array}$ \\
\hline Alexander et al, 1989 & USA & - & $\mathrm{CN}$ & 100 & $18-65(34)$ & $18-54(33)$ & Yes & No \\
\hline Andrews et al, 1990 & USA & - & MD & 147 & $---(38.7)$ & $---(43.4)$ & Yes & No \\
\hline Barrioset al, 1990 & Sweden & - & MD & 150 & $\mathrm{n} / \mathrm{a}$ & $\mathrm{n} / \mathrm{a}$ & Yes & No \\
\hline Caspar et al, 1991 & Germany & - & MD & 418 & $19-68(47.8)$ & $17-71(44)$ & Yes & No \\
\hline Crawshaw et al, 1984 & England & + & $\mathrm{CN}$ & 52 & $\mathrm{n} / \mathrm{a}$ & $\mathrm{n} / \mathrm{a}$ & Yes & No \\
\hline Dullerud et al, 1999 & Norway & - & APN & 158 & $18-65(41.8)$ & $18-68(38.8)$ & Yes & Yes \\
\hline Ejeskär et al, 1983 & Sweden & + & $\mathrm{CN}$ & 29 & 19-73 (42.1) & $21-51(36.6)$ & Yes & No \\
\hline Haines et al, 2002 & USA & + & APN & 34 & $---(35,4)$ & --- $(42.4)$ & Yes & No \\
\hline Henriksen et al, 1996 & Denmark & + & MD & 79 & $36-48(42.8)$ & $30-4639,7$ & Yes & No \\
\hline Hermantin et al, 1999 & USA & + & VMD & 60 & $18-67(40)$ & $15-66(39)$ & Yes & No \\
\hline Javid, 1995 & USA & - & $\mathrm{CN}$ & 200 & $\begin{array}{l}\text { Men 19-81 (38.7) women 24-73 } \\
(44.5)\end{array}$ & $\begin{array}{l}\text { Men 19-72 (36) women 17- } \\
55(39)\end{array}$ & Yes & Yes \\
\hline Kahanovitz et al, 1989 & USA & - & MD & 64 & $19-59(38)$ & $19-79(44)$ & Yes & No \\
\hline Launois et al, 1994 & France & - & $\mathrm{CN}$ & 146 & $\mathrm{n} / \mathrm{a}$ & $\mathrm{n} / \mathrm{a}$ & Yes & Yes \\
\hline Muralikuttan et al, 1992 & N. Ireland & + & $\mathrm{CN}$ & 92 & $19-60(39)$ & $20-53(36)$ & Yes & No \\
\hline Norton, 1986 & USA & - & $\mathrm{CN}$ & 105 & $24-64(42 / 44)$ & $20-67(38 / 42)$ & $\mathrm{n} / \mathrm{a}$ & No \\
\hline Nyström, 1987 & Sweden & - & MD & 130 & $---(43.9)$ & $---(39.7)$ & Yes & No \\
\hline Ramirezet al, 1985 & USA & - & $\mathrm{CN}$ & 80 & $16-76(42)$ & $22-74(41)$ & Yes & Yes \\
\hline Silvers, 1988 & Switzerland & - & MD & 500 & 14-87 (49) & $14-86(54)$ & Yes & No \\
\hline Schmid et al, 2016 & USA & - & MD & 540 & $---(42)$ & $---(41)$ & Yes & No \\
\hline Slotman et al, 1996 & USA & - & LD & 45 & $---(40)$ & $---(34.5)$ & Yes & No \\
\hline Tregonning et al, 1991 & Canada & - & $\mathrm{CN}$ & 268 & $22-62(41.3)$ & $20-65(39.9)$ & Yes & No \\
\hline Tullberg et al, 1993 & Sweden & + & MD & 60 & $18-64(38)$ & $17-59(40)$ & Yes & No \\
\hline van Alphen et al, 1989 & Netherlands & + & $\mathrm{CN}$ & 151 & $---(33.5)$ & $---(34)$ & Yes & No \\
\hline Weinstein, 1986 & USA & - & $\mathrm{CN}$ & 256 & $28-57(40.5)$ & $32-56(41.9)$ & Yes & No \\
\hline
\end{tabular}

Description of the studies. Characteristics of the included studies ('Design' is $+/$ - randomization) comparing lumbar diskectomy to other surgical procedures (CD $=$ Conventional diskectomy, $\mathrm{MD}=$ Microdiskectomy, $\mathrm{CN}=$ Chemonukleolysis, $\mathrm{APN}=$ Automated Percutanous Diskectomy, $\mathrm{VMD}=\mathrm{Video}$ assisted MD, LP=Laprascopic diskectomy.)

Table 3. Quality scores

\begin{tabular}{|c|c|c|c|c|c|c|c|c|c|c|c|c|c|c|c|c|c|c|}
\hline Study & Q1 & Q2 & Q3 & Q4 & Q5 & Q6 & Q7 & Q8 & Q9 & Q10 & Q11 & Q12 & Q13 & Diff & Hosp & Sick & Disabil & Cost \\
\hline Launois (1994) & + & $?$ & - & + & - & + & - & + & + & - & + & + & + & + & $\mathrm{CI}$ & $?$ & $?$ & $\mathrm{CI}$ \\
\hline Dullerud (1999) & + & + & - & + & + & + & - & - & - & - & + & - & + & + & $?$ & $?$ & $?$ & $\mathrm{CI}$ \\
\hline Ramirez (1985) & - & + & - & + & - & + & - & - & - & - & + & - & + & + & $\mathrm{CI}$ & $?$ & $?$ & $\mathrm{CI}$ \\
\hline Javid (1995) & + & + & - & - & + & + & - & - & - & - & - & - & - & + & $?$ & $?$ & $?$ & $\mathrm{CI}$ \\
\hline Alexander (1989) & - & + & + & + & + & + & & & & & & & + & & ND & $?$ & $?$ & $?$ \\
\hline Muralikuttan (1992) & + & + & + & - & + & + & & & & & & & + & & ND & $?$ & $\mathrm{CD}$ & $\mathrm{CD}$ \\
\hline Ejeskär (1983) & + & + & + & - & - & + & & & & & & & + & & $\mathrm{CI}$ & $?$ & $\mathrm{CD}$ & $?$ \\
\hline Tregonning (1991) & - & + & + & - & - & + & & & & & & & + & & $?$ & ND & ND & $?$ \\
\hline Van Alphen (1989) & $?$ & + & - & - & + & + & & & & & & & + & & $?$ & ND & $\mathrm{CD}$ & $?$ \\
\hline Weinstein (1986) & - & + & + & - & - & + & & & & & & & + & & $?$ & ND & $?$ & $?$ \\
\hline Crawshaw (1984) & + & + & - & - & - & + & & & & & & & - & & CI & $?$ & $\mathrm{CD}$ & $?$ \\
\hline Norton (1986) & $?$ & + & $?$ & - & - & - & & & & & & & - & & $?$ & $?$ & $?$ & $\mathrm{CD}$ \\
\hline Henriksen (1996) & + & + & + & + & + & + & & & & & & & + & & ND & $?$ & $?$ & $?$ \\
\hline Tullberg (1993) & + & + & - & + & + & + & & & & & & & + & & ND & ND & $?$ & $?$ \\
\hline Andrews (1990) & - & - & + & - & + & + & & & & & & & + & & $\mathrm{CI}$ & $\mathrm{CI}$ & $?$ & $?$ \\
\hline Caspar (1991) & - & - & - & + & + & + & & & & & & & + & & $\mathrm{CI}$ & $\mathrm{CI}$ & $\mathrm{CI}$ & $?$ \\
\hline Schmid (2016) & - & - & - & + & + & + & & & & & & & + & & CI & $?$ & $?$ & $?$ \\
\hline Silvers (1988) & - & + & - & - & - & + & & & & & & & + & & CI & CI & $?$ & $?$ \\
\hline Kahanovitz (1989) & - & + & - & - & - & + & & & & & & & + & & $\mathrm{CI}$ & ND & $?$ & $?$ \\
\hline Nyström (1987) & - & - & - & - & - & + & & & & & & & + & & $\mathrm{CI}$ & $\mathrm{CI}$ & $?$ & $?$ \\
\hline Barrios (1990) & - & - & - & - & - & + & & & & & & & - & & $\mathrm{CI}$ & $\mathrm{CI}$ & $?$ & $?$ \\
\hline Haines (2002) & + & + & + & + & - & + & & & & & & & + & & $?$ & $?$ & $?$ & $?$ \\
\hline Slotman (1996) & - & - & - & - & - & + & & & & & & & + & & $\mathrm{CI}$ & $?$ & $\mathrm{CI}$ & $\mathrm{CD}$ \\
\hline Hermantin (1999) & - & + & - & + & + & + & & & & & & & + & & $?$ & $\mathrm{CD}$ & $?$ & $?$ \\
\hline
\end{tabular}

Quality assessment (Q1-3: Patient selection/intervention, Q4-13: Economic evaluation, Diff-D.ii: Results). Columns Q1-13 refer to the applied quality criteria, as listed in table 1.Column 'Diff': Was there any difference reported in cost-effectiveness between the interventions? Columns 'Hosp', 'Sick', 'Disabil' and 'Cost' refer to 'Was there any difference in hospitalization days?', 'Was there any difference in days on sick leave?', Was there any difference in disability (prompting treatment)?' and 'Was there any difference in cost of intervention?', respectively. The cells list reported differences: 'CD' = a difference in favor of Conventional Diskectomy, 'CI' = a difference in favor of the Control Intervention, 'ND' = no difference was reported, '?' $=$ unknown, not reported or not applicable. 
Nine studies compared CD to MD [33-35,39,41,44-46,49] and outcome measures used were length of hospitalization in all studies, length of sick leave in six studies [34-36,44,46,49], disability in one study $^{35}$, and cost of intervention in one study [46].

One study [47] compared CD to laproscopic diskectomy (LD) using length of hospitalization, disability and cost of intervention as outcome measures.

One study [40] compared CD to video-assisted arthroscopic microdiskectomy (VAMD) and used length of sick leave as outcome measure.

Two studies $[28,38]$ compared CD to automated percutaneous diskectomy (APD), one [28] used cost of intervention as outcome measure, and the outcome measures of the other ${ }^{38}$ were not applicable in the present review.

Eleven studies originated from the USA $[29,30,32,33,38,39,41,43,4$ $6,47,51]$, twelve from Europe [28,31,34-37,39,42,44,45,49,50] and one from Canada [48].

\section{Results of the cost-effectiveness studies}

Of the four articles which included an economic evaluation, none were randomized.

Three studies compared CD to CNL, and 1 compared CD to ADP. The quality score of the studies varied considerably (see Table 2). However, all four studies favored the control intervention over CD. The results of the economic evaluations are described in the following section, listed in descending order of quality score: Launois, et al [31], Dullerud, et al. [28], Ramirez \& Javid [30] and Javid [29].

\section{Launois, et al}

A comparison study, examining the economic costs and quality of life following CNL versus CD.

Launois, et al did not randomize the groups or describe the dropout rate, and it is difficult to determine whether the groups were comparable at baseline, yet this study had the highest quality checklist score. Launois, et al [31] considered all the direct costs of each alternative intervention using decision modeling to estimate quality of life and calculate the amount of saved QALYs. Furthermore, the authors calculated the costs of each probable outcome and the 7-year follow-up strengthens the quality further.

The authors reported fewer hospitalization days in the CNL group, and about half the monetary costs of those associated with CD. However, $\mathrm{CD}$ produced slightly better clinical results compared to CNL.

\section{Dullerud, et al}

Dullerud, et al [28] compared the costs of APD to that of CD and scored well in the quality assessment of the intervention, but the economic evaluation was lacking.

They included the direct costs of the procedure but did not specify other costs. The direct costs were based on the Norwegian DRG internal reimbursement system rather than actual costs and were therefore based on a pre-defined, standard estimate cost for that procedure.

The authors concluded that nucleotomy is a minimally invasive procedure with low complication rates, which potentially has a short recovery period and, arguably, therefore could be more cost-effective than traditional surgical treatment for lumbar disk herniation.

\section{Ramirez and Javid} CD.

Ramirez and Javid [30] studied the cost-effectiveness of CNL versus

The study had shortcomings both in the quality assessment of the intervention and the economic evaluation. The authors reported costs based on claims from insurance companies and not actual costs. In addition, all patients included were selected and recruited from the same hospital and all cost parameters were extracted from hospital charges.

The conclusions were somewhat ambiguous due to the shortcoming of the study, but the authors speculate that there is a difference in favor of CNL with regards to fewer hospitalization days and cheaper intervention.

\section{Javid}

The study by Javid [29] is a comparison study of the effectiveness and economic burden of CNL compared to CD.

Assessment of this study revealed that the intervention was adequately described but the quality of the economic evaluation was substantially lacking. Only overall direct costs were reported, specified as hospital charge and professional charge, but did not describe basis of the calculations. Any additional costs were not reported.

The total costs for both interventions were reported, with and without additional costs of re-operations. The basis for a costeffectiveness analysis was in fact present, but as the authors presented no further analyses, it is debatable wether the study includes an actual cost-effectiveness analysis.

In any case, Javid [29] concluded that with adherence to strict criteria for selection and performance, CNL was less expensive than $\mathrm{CD}$, and resulted in fewer hospitalization days.

\section{Results of the studies reporting proxy measures for cost- effectiveness}

The twenty studies which did not include an economic evaluation lend support to the following conclusions: In general the quality of the studies is not very impressive (see Table 2), but the better the quality of the studies, the less difference concerning the outcome of the compared interventions was reported.

CD compared to CNL: Overall the studies found either no difference, or fewer hospitalization days and less disability in favor of CD. Seven studies $[32,36,37,42,43,48,50]$ recommended CD as the method of choice for lumbar disk herniation compared to CNL.

CD compared to MD: The majority of the studies found fewer hospitalization days [33-35,41,44-46] and fewer sick leave days [33$35,44,46]$ in favor of MD. None of the studies reported the cost of the intervention.

The study by Haines, et al [38] using APD was of good quality but did not include a sufficient number of patients to reach definitive conclusions.

The study by Slotman, et al [47] using LD reported fewer hospitalization days, less disability and lower costs in favor of the LD intervention.

The study by Hermantin, et al [40] using VAMD demonstrated fewer sick leave days in favor of VAMD compared to CD. 


\section{Discussion}

To our knowledge, this is the first literature review examining the cost-effectiveness of CD compared to other surgical techniques used for lumbar disk herniation.

The review demonstrates that the volume and quality of research is insufficient to draw firm conclusions. However, studies which include an economic evaluation favor the alternative interventions over CD. Studies using proxy measures of economic costs reported mixed results.

\section{Cost-effectiveness studies}

Generally, the four cost-effectiveness studies present a rather narrow perspective on cost-effectiveness, with a clear focus on direct costs of surgery. Detailed descriptions of indirect costs, costs associated with post-surgical care, rehabilitation, lost productivity, etc are lacking. As indirect costs are known to be significantly greater than direct costs in relation to low-back pain management [52], the economic evaluation in these four studies, is of limited value.

The four cost-effectiveness studies all supported the alternative surgical procedures over $\mathrm{CD}$. None of the studies were designed as randomized trials however and their conclusions should thus be tempered by the risk of selection bias.

Furthermore, the identification, measurement and estimation of costs in these studies were carried out in different settings, over different time periods, using different data sources and thus the external validity can be questioned.

Three of the four cost-effectiveness studies compared CD to CNL which, in Denmark at least is no longer in common use due to potential problems with allergic reactions. The fourth cost-effectiveness study compared CD to APD which is also an uncommon procedure.

\section{Studies reporting proxy measures for costs}

When compared to CNL $[32,36,37,42]$ and MD [33-35,39,44,46,49] no clear picture emerges for or against $\mathrm{CD}$, but it is noteworthy that the studies with the highest quality assessment $[32,39,42,49]$ all report no difference between techniques. It thus remains unclear which, if any method is superior. The review and meta-analysis by Kamper, et al [17] reached similar conclusions.

The studies investigating VAMD [40] and LD [47] suggest that these techniques can serve as an alternative to $\mathrm{CD}$, but underline that these are demanding techniques and therefore require a considerable amount of training. Arguably, this might suggest that the techniques are cost-effective in a longer prospective, but this is speculative and more research with longer follow-up periods would be needed to be able to support such a conclusions.

\section{Methodological considerations}

The present search strategy was developed in collaboration with an expert librarian with extensive experience in systematic literature reviews and search strategies. Nevertheless, of the included articles only 9 were retrieved from the original search strategy, while 15 where retrieved by manual perusal of reference lists. Arguably, this could be interpreted as an indication that the search strategy was insufficient - alternatively, that a majority of relevant manuscripts have been insufficiently indexed.

A well-established checklist for the economic evaluation ${ }^{13}$ was used, and both reviewers scored the articles by the checklist separately, before findings were compared and conferred with an experienced health economy expert (ED) to ensure correct assessment. Using the checklist by Drummond, et al [13] could potentially have resulted in lower ratings of studies which did not include an economic evaluation. Thus items related to economic evaluation were omitted where appropriate, to counter such bias and economic studies and proxy measure studies have been dealt with separately.

In this review we evaluated the literature on different surgical techniques, but obviously it was not possible to determine how the surgical techniques were actually performed, beyond the descriptions reported in the methodology sections. In many cases, this was simply reported as 'conventional diskectomy' and terms to that effect. The exact procedure of the surgical interventions may vary greatly and could therefore potentially influence the outcome. It is also likely that the surgical techniques have been substantially revised over the last 20 years. Considering the relatively old age of some studies included in this review, this may be of importance in the evaluation of outcomes.

\section{Future directions}

Further research: Arts, et al [53] published a study protocol with the aim of determining whether $\mathrm{MD}$ is more cost-effective than $\mathrm{CD}$ for patients with lumbar disk herniation. To our knowledge, the final results are not published, but the protocol is a good example of how future research in this field could be performed. Arts et $\mathrm{al}^{53}$ intend to randomize the patients prospectively, and consider the outcome measures (function, pain, quality of life, recovery, re-operation), in relation to costs. The costs include the direct medical costs, indirect productivity cost, work-efficiency, re-operation, complications, as well as other medical costs (physiotherapy, visits to general practitioners and medical specialists, nursing care and medication). Arguably, their suggested two-year follow-up may be insufficient, but in cost-effectiveness studies, indirect costs and societal costs ought to be included if possible.

\section{Conclusions}

On the basis of the available literature, there is little ground on which to make strong recommendations for one surgical procedure over another, at least in terms of cost-effectiveness. Generally speaking, studies were not of high quality and surgical techniques were only superficially described.

Nevertheless, on the basis of the literature at hand, the findings can be summarized as follows:

- The literature on CNL is conflicting, with economic evaluations suggesting that CNL has lower costs compared to CD, but conversely non-economic studies suggest better clinical outcomes of CD.

- No economic evaluation of MD compared to CD was found, but most (low quality) non-economic studies report fewer days in hospital or sick leave with MD, which arguably could translate to lower costs.

- Only very few studies report on LD, VAMP and APD and none provide a reliable basis for estimating their cost-effectiveness.

\section{Conflicts of interest}

No external financial or material support has been sought or received. The authors have no financial interests in the study outcome. The submitted manuscript is entirely the work of the listed authors -- no external parties have influenced the protocol, data collection, analysis or reporting of the current work.

We declare no conflicts of interest. 


\section{Ethics}

No institutional ethics approval is required for literature reviews.

\section{Acknowledgements}

The authors would like to acknowledge senior librarian Berit Elisabeth Alving for her expert guidance in relation to the literature search.

\section{References}

1. Søren Eiskjær MG, Karen Højmark, og Mikkel Andersen (2012) Rygkirurgi in Denmark Annual Report 2012 Danish Rygkirurgisk Selskab.

2. Institut SS (2014) Interaktiv DRK.

3. Søren Eiskjær MG, Karen Højmark, og Mikkel Andersen (2013) Rygkirurgi i Danmark Årsrapport 2013 Dansk Rygkirurgisk Selskab.

4. Sun EC, Wang JC, Endow K, Delamarter RB (2004) Adjacent two-level lumbar discectomy: Outcome and sf-36 functional assessment. Spine. 29: E22-E27. [Crossref]

5. Pappas CT, Harrington T, Sonntag VK (1992) Outcome analysis in 654 surgically treated lumbar disc herniations. Neurosurgery 30: 862-866. [Crossref]

6. Williams RW (1993) Lumbar disc disease. Microdiscectomy. Neurosurg Clin N Am 4: 101-108. [Crossref]

7. Kotilainen E (1994) Microinvasive lumbar disc surgery. A study on patients treated with microdiscectomy or percutaneous nucleotomy for disc herniation. Ann Chir Gynaecol Suppl 209: 1-50. [Crossref]

8. Postacchini F, Postacchini R (2011) Operative management of lumbar disc herniation: The evolution of knowledge and surgical techniques in the last century. Acta Neurochir Suppl 108: 17-21. [Crossref]

9. Garg B, Nagraja UB, Jayaswal A (2011) Microendoscopic versus open discectomy for lumbar disc herniation: A prospective randomised study. J Orthop Surg 19: 30-34. [Crossref]

10. Benz RJ, Garfin SR (2001) Current techniques of decompression of the lumbar spine. Clin Orthop Relat Res: 75-81. [Crossref]

11. Malter AD, Larson EB, Urban N, Deyo RA, Clark RE (1996) Cost-effectiveness of lumbar discectomy for the treatment of herniated intervertebral disc. Spine 21: 10481055. [Crossref]

12. Moher D, Liberati A, Tetzlaff J, Altman DG; PRISMA Group (2009) Preferred Reporting Items for Systematic Reviews and Meta-Analyses: The PRISMA Statement. BMJ 339: b2535. [Crossref]

13. Drummond MF, Stoddart GL, Torrance GW, O'Brien B (1997) Methods for the Economic Evaluation of Health Care Programmes.

14. Gibson JNA, Waddell G (2007) Surgical interventions for lumbar disc prolapse. Cochrane Database Syst Rev 24: CD001350. [Crossref]

15. Hoffman RM, Wheeler KJ, Deyo RA (1993) Surgery for herniated lumbar discs: a literature synthesis. J Gen Intern Med 8: 487-496. [Crossref]

16. Jacobs WC, Arts MP, Tulder MW van, Rubinstein SM, van Middelkoop M, et al. (2012) Surgical techniques for sciatica due to herniated disc, a systematic review. Eur Spine J 21: 2232-2251. [Crossref]

17. Kamper SJ, Ostelo RWJG, Rubinstein SM, Nellensteijn JM, Peul WC, et al. (2014) Minimally invasive surgery for lumbar disc herniation: A systematic review and metaanalysis. Eur Spine J 23: 1021-1043. [Crossref]

18. Lu Y, Qureshi SA (2014) Cost-effective studies in spine surgeries: a narrative review. Spine J 14: 2748-2762. [Crossref]

19. Lubelski D, Mihalovich KE, Skelly AC, Fehlings MG, Harrop JS, et al (2014) Is minimal access spine surgery more cost-effective than conventional spine surgery? Spine 39: S65-s74.

20. Luhmann D, Burkhardt-Hammer T, Borowski C, Raspe H (2005) Minimally invasive surgical procedures for the treatment of lumbar disc herniation. GMS Health Technol Assess 1: Doc07. [Crossref]

21. Nordby EJ, Wright PH (1994) Efficacy of chymopapain in chemonucleolysis. A review. Spine (Phila Pa 1976) 19: 2578-2583. [Crossref]

22. Payer M (2011) 'Minimally invasive' lumbar spine surgery: A critical review. Acta Neurochir (Wien). 153: 1455-1459. [Crossref]
23. Rasouli MR, Rahimi-Movaghar V, Shokraneh F, Moradi-Lakeh M, Chou R (2014) Minimally invasive discectomy versus microdiscectomy/open discectomy for symptomatic lumbar disc herniation. Cochrane Database of Systematic Reviews 9.

24. Richter EO, Ulm AJ, Peace DA, Henn JS (2004) Minimally invasive microdiscectomy. Oper Tech Neurosurg 7: 50-55

25. Stevens CD, Dubois RW, Larequi-Lauber T, Vader JP (1997) Efficacy of lumbar discectomy and percutaneous treatments for lumbar disc herniation. Soz Praventivmed 42: 367-379. [Crossref]

26. Teh J, Ostlere S (2004) Diagnostic and therapeutic percutaneous procedures in the spine. Rivista Neuroradiologia 17: 262-368.

27. Tulder MW van, Koes B, Seitsalo S, Malmivaara A (2006) Outcome of invasive treatment modalities on back pain and sciatica: An evidence-based review. Eur Spine $J$ 1: S82-92. 28

28. Dullerud R, Lie H, Magnaes B (1999) Cost-effectiveness of percutaneous automated lumbar nucleotomy. comparison with traditional macro-procedure discectomy. Interv Neuroradiol 5: 35-42. [Crossref]

29. Javid MJ1 (1995) Chemonucleolysis versus laminectomy. A cohort comparison of effectiveness and charges. Spine (Phila Pa 1976) 20: 2016-2022. [Crossref]

30. Ramirez LF, Javid MJ (1985) Cost effectiveness of chemonucleolysis versus laminectomy in the treatment of herniated nucleus pulposus. Spine (Phila Pa 1976) 10: 363-367. [Crossref]

31. Launois R, Henry B, Marty JR, et al. (1994) Chemonucleolysis versus surgica discectomy for sciatica secondary to lumbar disc herniation. A cost and quality-of-life evaluation. Pharmacoeconomics 6: 453-463. [Crossref]

32. Alexander AH, Burkus JK, Mitchell JB, Ayers WV (1989) Chymopapain chemonucleolysis versus surgical discectomy in a military population. Clin Orthop Relat Res 244: 158-165. [Crossref]

33. Andrews DW, Lavyne MH (1990) Retrospective analysis of microsurgical and standard lumbar discectomy. Spine (Phila Pa 1976) 15: 329-335. [Crossref]

34. Barrios C, Ahmed M, Arrótegui J, Björnsson A, Gillström P (1990) Microsurgery versus standard removal of the herniated lumbar disc a 3-year comparison in 150 cases. Acta Orthop Scand 61: 399-403. [Crossref]

35. Caspar W, Campbell B, Barbier DD, Kretschmmer R, Gotfried Y (1991) The caspar microsurgical discectomy and comparison with a conventional standard lumbar disc procedure. Neurosurgery 28: 78-86. [Crossref]

36. Crawshaw C, Frazer AM, Merriam WF, Mulholland RC, Webb JK (1984) A comparison of surgery and chemonucleolysis in the treatment of sciatica. A prospective randomized trial. Spine (Phila Pa 1976) 9: 195-198. [Crossref]

37. Ejeskar A, Nachemson A, Herberts P, Lysell E, Andersson G, et al. (1983) Surgery versus chemonucleolysis for herniated lumbar discs. a prospective study with random assignment. Clin Orthop Relat Res 174: 236-242. [Crossref]

38. Haines SJ, Jordan N, Boen JR, Nyman JA, Oldridge NB, et al. (2002) Discectomy strategies for lumbar disc herniation: Results of the lapdog trial. J Clin Neurosci 9: 411-417. [Crossref]

39. Henriksen L, Schmidt K, Eskesen V, Jantzen E (1996) A controlled study of microsurgical versus standard lumbar discectomy. $B r J$ Neurosurg 10: 289-293. [Crossref]

40. Hermantin FU, Peters T, Quartararo L, Kambin P (1999) A prospective, randomized study comparing the results of open discectomy with those of video-assisted arthroscopic microdiscectomy. J Bone Joint Surg Am 81: 958-965. [Crossref]

41. Kahanovitz N, Viola K, Muculloch J (1989) Limited surgical discectomy and microdiscectomy. a clinical comparison. Spine (Phila Pa 1976) 14: 79-81. [Crossref]

42. Muralikuttan KP, Hamilton A, Kernohan WG, Mollan RA, Adair IV (1992) A prospective randomized trial of chemonucleolysis and conventional disc surgery in single level lumbar disc herniation. Spine (Phila Pa 1976) 17: 381-387. [Crossref]

43. Norton WL (1986) Chemonucleolysis versus surgical discectomy. comparison of costs and results in workers' compensation claimants. Spine (Phila Pa 1976) 11: 440-443. [Crossref]

44. Nystrom B (1987) Experience of microsurgical compared with conventional technique in lumbar disc operations. Acta Neurol Scand 76: 129-141. [Crossref]

45. Schmid SL, Wechsler C, Farshad M, Antoniadis A, Ulrich NH, et al. (2016) Surgery for lumbar disc herniation: Analysis of 500 consecutive patients treated in an interdisciplinary spine centre. J Clin Neurosci 27: 40-43. [Crossref] 
46. Silvers HR (1988) Microsurgical versus standard lumbar discectomy. Neurosurgery 22: 837-841. [Crossref]

47. Slotman GJ, Stein SC (1996) Laparoscopic 15-s1 diskectomy: A cost-effective, minimally invasive general surgery-neurosurgery team alternative to laminectomy. $\mathrm{Am}$ Surg 62: 64-68. [Crossref]

48. Tregonning GD, Transfeldt EE, McCulloch JA, Macnab I, Nachemson A (1991) Chymopapain versus conventional surgery for lumbar disc herniation. 10-year results of treatment. J Bone Joint Surg Br 73: 481-486. [Crossref]

49. Tullberg T, Isacson J, Weidenhielm L (1993) Does microscopic removal of lumbar disc herniation lead to better results than the standard procedure? Results of a one-year randomized study. Spine (Phila Pa 1976) 18: 24-27. [Crossref]
50. van Alphen HA, Braakman R, Bezemer PD, Broere G, Berfelo MW (1989) Chemonucleolysis versus discectomy: a randomized multicenter trial. J Neurosurg 70: 869-875. [Crossref]

51. Weinstein J, Spratt KF, Lehmann T, McNeill T, Hejna W (1986) Lumbar disc herniation. A comparison of the results of chemonucleolysis and open discectomy after ten years. J Bone Joint Surg Am 68: 43-54. [Crossref]

52. Katz JN (2006) Lumbar disc disorders and low-back pain: socioeconomic factors and consequences. J Bone Joint Surg Am 88 Suppl 2: 21-24. [Crossref]

53. Arts MP, Peul WC, Brand R, Koes BW, Thomeer RT (2006) Cost-effectiveness of microendoscopic discectomy versus conventional open discectomy in the treatment of lumbar disc herniation: A prospective randomised controlled trial [isrctn51857546] BMC Musculoskelet Disord 7: 42. [Crossref]

Copyright: (C2018 Thorsen MTH. This is an open-access article distributed under the terms of the Creative Commons Attribution License, which permits unrestricted use, distribution, and reproduction in any medium, provided the original author and source are credited. 